\title{
Implementasi Konsep Halalan Thayyiban pada Rumah Makan Wong Solo Kota Palangka Raya
}

\author{
Ahmad Dhea Satria ${ }^{1 *}$, Syarifuddin ${ }^{1}$ \\ Magister Ekonomi Syariah, Institut Agama Islam Negeri \\ Palangka Raya, Kalimantan Tengah, Indonesia \\ *Corresponding author: satria.ss85@gmail.com
}

\author{
Article history \\ Received, 17 April 2021 \\ Revised 1, 03 Mei 2021 \\ Revised 2, 20 Juli 2021 \\ Accepted, 29 July 2021
}

\begin{abstract}
This article tries to look at the phenomenon of development, A business that is required to have sensitivity to any changes that occur and put orientation to consumer satisfaction. Moreover, in Indonesia, which is majority Muslim, businesses are faced with sensitivity to halal food. This method of writing uses a qualitative descriptive approach, which will be expected to be able to describe of implementing the concept of halalan thayyiban. the results showed a special strategy used to attract consumers to come buy Wong Solo restaurant products. Halalan thayyiban as a marketing strategy of course not only the writing is displayed but also to the practice of application, both for owners, employees, and to all consumers also halalan thayyiban must be on all aspects of human life. Consumer response to the application of halalan thayyiban concept received a positive response from consumers. Considering Wong Solo restaurant not only makes the concept of halalan thayyiban as a slogan to attract consumer interest, but also as a slogan in life.
\end{abstract}

Keyword: Implementasion, Halalan Thayyiban, Restaurant Wong Solo

\section{Abstrak}

Artikel ini mencoba melihat fenomena perkembangan, Bisnis yang dituntut memiliki kepekaan terhadap setiap perubahan yang terjadi dan menempatkan orientasi pada kepuasan konsumen. Apalagi di Indonesia yang mayoritas muslim, bisnis dihadapkan pada kepekaan terhadap makanan halal. Metode penulisan ini menggunakan pendekatan deskriptif kualitatif, yang diharapkan mampu menggambarkan implementasi konsep halalan thayyiban. hasil penelitian menunjukkan strategi khusus yang digunakan untuk menarik konsumen untuk datang membeli produk restoran Wong Solo. Halalan thayyiban sebagai strategi pemasaran tentunya tidak hanya tulisan yang ditampilkan tetapi juga pada praktik aplikasi, baik untuk pemilik, karyawan, maupun kepada seluruh konsumen juga halalan thayyiban harus pada semua aspek kehidupan manusia.Respon konsumen terhadap penerapan konsep halalan thayyiban mendapat respon positif dari konsumen.Mengingat restoran Wong Solo tidak hanya menjadikan konsep halalan thayyiban sebagai slogan untuk menarik minat konsumen, tetapi juga sebagai slogan dalam hidup.

Kata kunci: Implementasi, Halalan Thayyiban, Rumah Makan Wong Solo

\section{Cite this article:}

Satria, Ahmad Dhea, Syarifuddin (2021).Implementasi Konsep

Halalan Thoyyiban pada Rumah Makan Wong Solo Kota

Palangka Raya, Jurnal Al-Qardh, 6(1), 45-51.

http://doi.org/10.23971/jaq.v6i1.2846

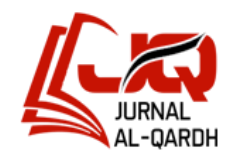

pISSN: $2354-6034$

eISSN: $2599-0187$ 


\section{Pendahuluan}

Dewasa ini, makanan dan minuman merupakan salah satu potensi bisnis dengan pertumbuhan yang semakin tinggi setiap harinya. Hal ini karena makanan dan minuman merupakan suatu kebutuhan utama semua orang dari berbagai kalangan.Hal ini lah yang menyebabkan pelayananmakanan semakin berkembangkarena sering dikaitkan dengan animo masyarakat yang semakin tinggi. Hal tersebut salah satu yang menjadi pemicu karena seseorang yang memiliki aktivitas diluar rumah. Mereka lebih menyukai suatu makanan yang sifatnya praktis dan instan.

Salah satunya contohnya yakni dengan mencari makanan dan minuman di luar rumah. kebiasaan makan dan minum di luar rumah menjadi bagian yang tidak dapat dipisahkan dari kehidupan masyarakat modern yang fungsinya semakin bertambah luas dari fungsi utamanya. Hal tersebut juga yang membuat rumah makan kian ramai dan banyak.

Melihat kian ramainya rumah makan membuat individu harus lebih selektif dalam memilih makanan yang hendak dikunjungi, dan harus lebih jeli melihat aspek sehat dan halalnya. Terlebih lagi bagi umat muslimyang harus memperhatikan aspek-aspek tersebut dalam setiap mengkonsumsi makanan. Karena sesuai dengan perintah Al-Quran "Dan makanlah makanan yang halal lagi baik dari apa yang Allah telah rezekikan kepadamu, dan bertakwalah kepada Allah yang kamu beriman kepada-Nya”. (Q.S AlMaidah 5: 88), atau yang sering digaungkan yakni Halalan Thayyiban.

Selain itu Islam merupakan agama yang membawa petunjuk bagi manusia serta memberi kesejahteraan bagi manusia di dunia maupun di akhrirat. Petunjuk-petunjuk tersebut umumya bersifat global, sehingga tidak pada tempatnya menuntut dari sumber ajaran Islam yaitu AlQur'an dan Hadist tentang petunjuk-petunjuk praktis dan terperinci yang menyangkut berbagai aspek kehidupan.

Para ulama Islam sepakat bahwa ajaran agama Islam bertujuan untuk memlihara lima hal pokok yaitu: agama, jiwa, akal, kehormatan dan kesehatan. Setiap usaha yang mendukung tercapainya salah satu diantara tujuan tersebut walaupun belum ditemukan dalam kitab suci al-Qur'an dan al-Sunnah, mendapat dukungan penuh dari ajaran Islam.

Salah satu yang memperhatikan aspek kehalalan dan kebaikan yaitu Rumah makan Wong Solo yang salah satu warung makan mempunyai motto Halalan Thayyiban, hal demikian menjadikan makanan yang disajikan merupakan bahan-bahan yang berkualitas dan tentu halal, diproses dengan memperhatikan hukum-hukum dalam agama Islam. Sisi menarik lainnya dari rumah makan ini yakni dari segi operasionalnya yang mana karyawannya melaksanakan pekerjaannya dengan secara religius contohnya seperti melakukan sholat lima waktu, dan pengajian rutin.

Melihat motto halalan thayyiban dan opersional rumah makan wong solo yang religious peneliti tertarik mengkaji lebih dalam mengenai konsep makanan halalan dan thayyiban melalui sebuah artikel yang berjudul strategi penerapan konsep halalan thayyiban pada rumah makan wong solo.

Didalam pelayanannya, rumah makan Wong Solo menerapkan total service yaitu melayani konsumen bagai "Raja". Semua pelayanan mulai dari pemesanan hingga kepada pembayaran dilakukan oleh karyawan. Target dari rumah makan Wong Solo yaitu golongan kelas menengah kebawah dengan menu khas Tradisional. ${ }^{1}$

\footnotetext{
${ }^{1}$ Observasi terhadap Manajer Wong Solo cab Palangka Raya di Palangka Raya 10 Januari 2018.
} 


\section{Metode Penelitian}

Penelitian ini adalah penelitian deskriptif yang mana tujuannya untuk memberikan suatu gambaran mengenai subjek penelitian berdasarkan data yang diperoleh dari subjek yang diteliti yang mana hal ini dilakukan untuk melakukan hipotesis. Teknik pengumpulan data yang digunakan oleh peneliti adalah observasi dan wawancara. Adapun yang diobservasi dalam penelitian ini yaitu rumah makan wong solo dengan nuansa yang islami sehingga hal ini menarik perhatian dari peneliti sedangkan yang diwawancara dalam penelitian ini adalahmengenai strategi manajemen rumah makan wong solo yang mana mereka menerapkan sebuah konsep yang menarik perhatian khususnya konsumen muslim yaitu halalan thayyiban.Adapun subjek-subjek dari penelitian ini yaitu pihak manajemen rumah makan wong solo. Subjek ditentukan berdasarkan teknik purposive sampling. Peneliti memasuki dunia subjek dan melakukan interaksi terus menerus dengan subjek, dan mencari sudut pandang subjek.

Table 1.1 Responden

\begin{tabular}{|l|l|l|}
\hline No & Nama & Keterangan \\
\hline 1 & M. Salafuddin & Manager RM wong solo cab. Palangka Raya \\
\hline 2 & Irfan & Karyawan yang telah bekerja selama 9 tahun \\
\hline 3 & Sahadam & Karyawan yang telah bekerja selama 11 tahun \\
\hline 4 & Ibu Suharti & Selaku konsumen rumah makan wong solo \\
\hline 5 & Bapak Ifan & Selaku konsumen rumah makan wong solo \\
\hline \multicolumn{2}{|c|}{ Sumber: Subjek penelitian yang telah diolah oleh peneliti }
\end{tabular}

\section{Hasil dan Diskusi \\ Konsep Halalan Thoyyiban pada Rumah Makan Wong Solo}

Makanan dan minuman merupakan suatu kebutuhan yang sangat penting bagi manusia.Makan sejatinya untuk menghilangkan rasa lapar, keberlangsungan hidup dan kesanggupan untuk menunaikan suatu kewajiban.Oleh karenanya manusia membanting tulang serta bekerja keras untuk dapat menyambung kehidupan. Walaupun bahan makanan sudah tersedia di bumi ini akan tetapi juga harus berusaha mencari, mengumpulkan, serta mengolah nya menjadi suatu makanan yang siap disajikan.

Setiap manusia diperintahkan untuk mengkonsumsi yang halal dibumi ini dan tidak semua yang ada dibumi berarti halal.Oleh karena itu Allah SWT memerintahkan mengkonsumsi makanan yang dihalalkan.

Halal mempunyai arti diijinkan ataupun diperbolehkan, sedangkan haram merupakan hal yang dilarang oleh agama. Contohnya seorang muslim dilarang untuk mengkonsumsi babi, alkohol, darah, bangkai, serta daging hewan yang tidak sesuai dengan ajaran agama islam. ${ }^{2}$

Halal secara ringkas yaitu sesuatu yang diperbolehkan, dilakukan, digunakan, diusahakan, karena telah terurai tali atau ikatan yang mencegahnya atau unsur yang membahayakan dengan memperhatikan cara memperolehnya yang sesuai dengan ajaran Islam. ${ }^{3}$

Menurut Qardhawi Agama Islam merupakan agama yang sangat bijak dalam mengatur umatnya agar tidak memakan makanan yang haram dengan menjelaskan semua yang halal dimakan maupun yang diharamkan. Allah telah menciptakan bumi

\footnotetext{
${ }^{2}$ Yulfan Arif Nurohman and Rina Sari Qurniawati, "Keputusan Pembelian Produk Makanan Halal Di Lingkungan IAIN Surakarta," Among Makarti 12, no. 24 (2019).

${ }^{3}$ Siska Lis Sulistiani, "Analisis Maqashid Dalam Pengembangan Hukum Industri Halal Di Indonesia," Law and Justice 3, no. 2 (2018).
} 


\section{Implementasi Konsep Halalan Thoyyiban \\ pada Rumah Makan Wong Solo Kota Palangka Raya}

lengkap dengan isinya agar manusia dapat memilih dan tidak mengikuti langkahlangkah syaitan yang selalu menggoda manusia untuk mengikuti jalanya. ${ }^{4}$

Halal dan baik atau disebut halalan thayyiban merupakan syarat mutlak yang harus dilaksanakan oleh setiap muslim. Halal disini dijelaskan bahwa hal yang dibolehkan dan tidak bertentangan dengan agama islam. Sedangkan thayyib lebih kepada suatu kualitas produk, yang bermanfaat kepada kesehatan dan tidak membahayakan bagi setiap orang yang mengkonsumsinya. ${ }^{5}$

Memakan makanan yang halal dan baik merupakan suatu perintah yang wajib bagi umat muslim dan beriman. Karena memakan makanan yang halal dan baik merupakan suatu hal yang bertentangan dengan kehendak syaiton yang ingin menjerumuskan orang muslim kepada yang haram. ${ }^{6} \mathrm{Jadi}$ dapat disimpulkan makanan halal dan baik bukan hanya kewajiban bagi setiap orang untuk melaksanakannya akan tetapi juga mengandung manfaat bagi seseorang yang mengkonsumsinya.

Tafsir depag RI mengatakan bahwa kata halalan diberi kata sifat thayyiban oleh Allah, artinya makanan yang halal Allah adalah makanan yang berguna bagi tubuh; tidak merusak, tidak menjijikan, enak, tidak kadaluarwa, dan tidak bertentangan dengan perintah Allah, karena tidak diharamkan, sehingga menjadi illah (alasan dihalalkan sesuatu dari makanan). ${ }^{7}$

Secara Komprehensif makanan dan minuman halal merupakan suatu kebaikan pada setiap aspek seperti aspek kesehatan, aspek kebersihan, kehigienisan dan baik serta benar secara moral. Kemudian hal tersebut akan memunculkan kesadaran akan lingkungan serta peduli dengan semuaan yang Allah SWT ciptakan. Implikasinya kesadaran akan halal akan mendorong moralitas seseorang dalam apa pun yang dikerjakannya. $^{8}$

Kesadaran akan halal sangat penting bagi umat muslim, karena kesadaran dalam konteks halal mengerti mengenai apa yang baik atau boleh dikonsumsi dan mengerti tentang apa yang buruk dan tidak boleh dikonsumsi sesuai dengan ajaran agama Islam yang bersumber kepada Al-Quran dan Hadits. ${ }^{9}$

Beranjak dari hal tersebut Rumah makan Wong Solo mempunyai konsep khusus dalam melabeli produknya yaitu dengan tulisan halalan thoyyiban. Hal ini merupakan bagian dari pemasaran Islami yang rumah makan wong solo terapkan yaitu strategi pemasaran yang berlandaskan nilai-nilai keislaman. Hal ini yang menjadi daya tarik dari rumah makan tersebut, sehingga konsumen yang ingin mencari makanan yang benarbenar terjamin kehalalannya akan merasa aman makan dirumah makan tersebut, karena dari bahan baku hingga penyajian diperhatikan secara detail sehingga label Halalan Thayyiban atau halal dan baik itu dapat benar-benar dijalankan sesuai dengan nilai-nilai

\footnotetext{
${ }^{4}$ Ahmad Izzuddin, "Pengaruh Label Halal, Kesadaran Halal Dan Bahan Makanan Terhadap Minat Beli Makanan Kuliner," Penelitian Iptek 3, no. 2 (2018).

${ }^{5}$ Ira Yanti, “Analisis Pengaruh Faktor Psikologi Dan Religious Perilaku Msulimah Kota Medan Terhadap Konsumsi Kosmetik Halal Dan Baik," At-Tawassuth 3, no. 2 (2018).

${ }^{6}$ Zulkifli and Mualimin Mochammad Sahid, "Pensijilan Halal: Prosedur Dan Implementasi Di Indonesia," Malaysian Journal Syariah Dan Law 8, no. 2 (2018).

${ }^{7}$ Kementrian Agama Republik Indonesia, Kesehatan Dalam Perspektif Al-Quran( Tafsir Al-Quran Tematik) Seri V, 2009.

${ }^{8}$ Hendri Hermawan Adinugraha and Mila Sartika, "Halal Lifestyle Di Indonesia," An-Nisbah 5, no. 2 (2019).

${ }^{9}$ Talisa Rahma Pramintasari and Indah Fatmawati, "Pengaruh Keyakinan Religious, Peran Sertifikasi Halal, Paparan Informasi, Dan Alasan Kesehatan Terhadap Kesadaran Masyarakat Pada Produk Makanan Halal," Jurnal Fakultas Ekonomi Universitas Muhammadiyah Yogyakarta 8, no. 1 (2017).
} 
islami yang sudah dirancang oleh tim manajemen dari perusahaan rumah makan wong solo tersebut.

\section{Penerapan Konsep Halalan Thayyibanpada Rumah Makan Wong Solo}

Rumah makan Ayam Bakar Wong Solo merupakan rumah makan yang bergerak di jasa kuliner, rumah makan wong solo pertama kali berdiri pada tahun 1991 yang langsung kendalikan ownernya yaitu Bapak Puspo Wardoyo dan berkantor pusat di kota Medan dengan cabang hampir di seluruh provinsi di Indonesia. Beliau awalnya adalah seorang mantan guru SMA Perguruan Wahidin Bagan Si Api-api, kemudian beliau menjadi berwirausaha dengan membuka ayam bakar kaki lima di jalan SMA 2 Padang Golf Polonia Medan. Rumah Makan Ayam Bakar Wong Solo sendiri merupakan salah satu rumah makan tradisional besar yang bermoto "Halalan Thayyiban" yang mana halal dari segi bahan-bahan produknya dan juga baik dari segi aspek prosesnya hingga pelayanannya. meskipun menggunakan ayan bakar bukan berarti produk-produk yang mereka jual hanya sebatas ayam bakar saja akan tetapi tersedia juga berbagai menu seperti ikan serta sayur-sayuran dengan khas tradisonal.

Rumah makan Wong Solo mempunyai strategi khusus untuk menarik minat dari pangsa pasarnya. Strategi pemasaran yang rumah makan wong solo terapkan yaitu strategi pemasaran yang berlandaskan nilai-nilai keislaman. Hal ini yang menjadi daya tarik dari rumah makan tersebut, sehingga konsumen yang ingin mencari makanan yang benar-benar terjamin kehalalannya akan merasa aman makan dirumah makan tersebut, karena dari bahan baku hingga penyajian diperhatikan secara detail sehingga label Halalan Thayyiban atau halal dan baik itu dapat benar-benar dijalankan sesuai dengan nilai-nilai islami yang sudah dirancang oleh tim manajemen dari perusahaan rumah makan wong solo tersebut.

Rumah makan Wong Solo merupakan rumah makan yang berkonsep islami dan berusaha menerapkan hal tersebut sesuai dengan tuntunan syariat. Rumah makan Wong Solo juga mewajibkan karyawannya menggunakan pakaian yang syar'i, hal ini dilakukan agar dapat menciptakan suasana yang benar -benar Islami. ${ }^{10}$

Sejatinya makanan halal haruslah memenuhi 2 kretaria yang pertama halal dari segi dzatnya yang mana seluruh yang ada dibumi ini merupakan halal dikonsumsi kecuali beberapa jenis hewan dan tumbuhan yang disebut dalam Al-Quran, seperti: babi, darah, dan bangkai. Lalu hewan yang disembelih tanpa menyebut nama Allah atau atas nama selain Allah, hewan dicekik, yang dipukul, ditanduk hingga diterkam binatang buas kecuali sempat dilakukan sembelih. Adapun jenis-jenis nabati yang diharamkan contohnya yaitu sepertikhamr yang mana mengkonsumsi khamr dapat memabukkan seseorang hal ini diharamkan oleh syariat islam. ${ }^{11}$

Dalam surah Al-Maidah ayat 88 Allah SWT memerintahkan kita untuk mengkonsumsi makanan halal dan baik.Baik atau thayyib diletakkan setelah kata halal karena keduanya saling memiliki keterkaitan yaitu halal berarti yang dibolehkan dalam konteks makanan boleh untuk dikonsumsi.sedangkan thayyib berarti baik, yang mana seorang muslim mengkonsumsi makanan tidak hanya yang halal akan tetapi juga memperhatikan aspek-aspek kebaikan dan kesehatan didalamnya. Menurut Yusuf

\footnotetext{
${ }^{10}$ Elida Elfi Barus and Nuriani, "Implementasi Etika Bisnis Islam (Studi Pada Rumah Makan Wong Solo Medan)," Jurnal Perspektif Ekonomi Darusallam 2, no. 2 (2016).

${ }^{11}$ Tamimah et al., "Halalan Thayyiban: The Key Of Successgul Halal Food Indusry Deloment,"

Ulûmunâ : Jurnal Studi Keislaman 4, no. 2 (2018).
} 


\section{Implementasi Konsep Halalan Thoyyiban \\ pada Rumah Makan Wong Solo Kota Palangka Raya}

Qardhawi thayyib diartikan dengan makanan yang proposional dan tidak membahayakan bagi fisik serta akal bagi orang yang mengkonsumsinya. ${ }^{12}$

Rumah makan wong solo kota palangka raya mempunyai strategi khusus dalam menarik minat dari konsumen, sehingga apa yang diinginkan oleh manajemen rumah makan wong solo terwujud, seperti melakukan promosi melalui media masa, perencanaan produk yang hal tersebut dibuat oleh rumah wong solo pusat dengan pengawasan yang sangat ketat, serta penetapan harga yang kompetitif dengan keadaan pasar. Rumah makan wong solo juga menerapkan totalitas terhadap konsumennya hal ini berdampak kepada kepuasan konsumen. Dengan demikian strategi pemasaran serta segmen pasar yang di targetkan diharapkan tim manajemen dapat memberikan keuntungan yang maksimal.

Terdapat beberapa langkah yang dilakukan rumah makan wong solo dalam menerapkan konsep halalan thayyiban. pertama, ditinjau dari bahan bakunya menggunakan barang atau bahan yang halal, dalam memfilterisasi suatu produknya, pihak manajemen wong solo memilih agen/produsen/perusahaan yang memiliki sertifikasi halal. Menurut keterangan dari salah satu karyawan rumah makan wong solo kota Palangka Raya minimal dalam memilih produk atau bahan baku harus memiliki labelisasi halal karena hal tersebut yang jadi jaminan bagi manajemen rumah makan wong solo atas sajian yang mereka makanan yang mereka sajikan.

Kedua, penerapan konsep halalan thayyiban, tidak hanya melihat dari segi cara mendapatkan bahan bakunya tapi juga melihat dari prosesnya mulai dari proses membersihkannya, memasak hingga mensajikan. Kesemuaan hal tersebut memperhatikan aspek-aspek higenis, kebersihan serta kesahatan. Berdasarkan hasil keterangan pihak manajemen rumah makan wong solo bahwasanya halalan thayyiban, meski ayam dalam prosesnya tidak dilakukan penyembilhan langsung namun menggunakan ayam yang telah di potong oleh produsen lain yang memiliki sertifikasi halal. Selanjutnya sewaktu proses pembersihan hingga proses pemasakan harus baik semua. Langkah-langkah diatas bertujuan untuk menyajikan makanan yang halal dan thayyib untuk masyarakat kota Palangka Raya, disatu sisi juga sebagai strategi yang dilakukan untuk menarik konsumen pada umumnya terkhusus masyarakat muslim.

Strategi yang dilakukan oleh rumah makan wong solo mendapat tanggapan dari beberapa konsumen yang merespon dengan baik, diantaranya menagatakan bahwa makanan yang disajikan mereka yakini makanan-makanan yang halal, hal tersebut membuat konsumen meresa aman dan tenang karena makanan yang dikonsumsi disajikan dengan cara yang halal dan baik. Disamping itu, tidak hanya dari segi sajian makanan, namun respon baik para konsumen juga hadir dari segi layanan yang dilakukan, mulai dari tempatnya yang bersih dan nyaman hingga para karyawan yang ramah, sopan dan menggunakan atribut yang sesuai dengan tuntunan Islam (menutup aurat).

\section{Kesimpulan}

Konsep halal dan tayyiban merupakan dua konotasi nama yang sinonim dan berkait antara satu sama lain. Halal yakni dibenarkan oleh agama baik secara dzat maupun memperolehnya.Sedangkan thayyibyaitu harus memperhatikan aspek-aspek kesehatan dari makanan tersebut. Pada dasarnya termasuk thayyib dalam Islam menyangkut masalah-masalah yang berkaitan dengan kesehatan dan kebaikan manusia. Penerapan konsep halalan thayyiban pada rumah makan wong solo Terdapat beberapa

\footnotetext{
${ }^{12}$ Mochammad Novi RIfa'I, "Promosi Makanan Halal Di Kota Taipei, Taiwan," Falah Jurnal Ekonomi Syariah 3, no. 1 (2018).
} 
langkah yang dilakukan rumah makan wong solo dalam menerapkan konsep halalan thayyiban. pertama, ditinjau dari bahan bakunya menggunakan barang atau bahan yang halal, dalam memfilterisasi suatu produknya, pihak manajemen wong solo memilih agen/produsen/perusahaan yang memiliki sertifikasi halal. Kedua, penerapan konsep halalan thayyiban, tidak hanya melihat dari segi cara mendapatkan bahan bakunya tapi juga melihat dari prosesnya mulai dari proses membersihkannya, memasak hingga mensajikan. Kesemuaan hal tersebut memperhatikan aspek-aspek higenis, kebersihan serta kesahatan. Berdasarkan hasil keterangan pihak manajemen rumah makan wong solo bahwasanya halalan thayyiban, meski ayam dalam prosesnya tidak dilakukan penyembilhan langsung namun menggunakan ayam yang telah di potong oleh produsen lain yang memiliki sertifikasi halal. Selanjutnya sewaktu proses pembersihan hingga proses pemasakan harus baik semua

\section{Daftar pustaka}

Barus, E. E., \& Nuriani. (2016). Implementasi Etika Bisnis Islam (Studi Pada Rumah Makan Wong Solo Medan). Jurnal Perspektif Ekonomi Darusallam, 2(2).

Hendri Hermawan Adinugraha, \& Sartika, M. (2019). Halal Lifestyle Di Indonesia. AnNisbah, 5(2).

Izzuddin, A. (2018). Pengaruh Label Halal, Kesadaran Halal dan Bahan Makanan Terhadap Minat Beli Makanan Kuliner. Penelitian Iptek, 3(2).

Kementrian Agama Republik Indonesia. (2009). Kesehatan dalam Perspektif Al-Quran( Tafsir Al-Quran Tematik) Seri V.

Lubis, Nurul Izzah. (2019), Analisis Loyalitas Konsumen Produk Berlabel Halal, Jurnal Al-Qardh, Vol. 4, No. 1, pp. 51-59, doi: https://doi.org/10.23971/jaq.v4i1.1661

Pramintasari, T. R., \& Fatmawati, I. (2017). pengaruh keyakinan religious, peran sertifikasi halal, paparan informasi, dan alasan kesehatan terhadap kesadaran masyarakat pada produk makanan halal. Jurnal Fakultas Ekonomi Universitas Muhammadiyah Yogyakarta, 8(1).

RIfa'I, M. N. (2018). Promosi Makanan Halal Di Kota Taipei, Taiwan. Falah Jurnal Ekonomi Syariah, 3(1).

Rahmaniar., Farid, F.M., dan Herliani, Yeni. (2017), Pengaruh Perilaku Konsumen dan Label Halal Produk Makanan Rumah Tangga terhadap Keputusan Konsumsi di Palangka Raya, Jurnal Al-Qardh, Vol. 2, No.1, pp. 60-65, doi: https://doi.org/10.23971/jaq.v2i1.827

Sulistiani, S. L. (2018). Analisis Maqashid dalam Pengembangan Hukum Industri Halal Di Indonesia. Law and Justice, 3(2).

Tamimah, Herianingrum, S., Ratih, I. S., \& Rofi'ah, K. (2018). Halalan Thayyiban: The Key Of Successgul Halal Food Indusry Deloment. Ulûmunâ: Jurnal Studi Keislaman, 4(2).

Yanti, I. (2018). Analisis Pengaruh Faktor Psikologi Dan Religious Perilaku Msulimah Kota Medan Terhadap Konsumsi Kosmetik Halal Dan Baik. At-Tawassuth, 3(2).

Yulfan Arif Nurohman, \& Qurniawati, R. S. (2019). Keputusan Pembelian Produk Makanan Halal Di Lingkungan IAIN Surakarta. Among Makarti, 12(24).

Zulkifli, \& Sahid, M. M. (2018). Pensijilan Halal: Prosedur Dan Implementasi Di Indonesia. Malaysian Journal Syariah Dan Law, 8(2). 